\title{
Validation Method for Digital Flow Meter for Fuel Vendors
}

\author{
Prisma Megantoro ${ }^{1}$, Danar Aulia Husnan ${ }^{2}$, Mian Usman Sattar ${ }^{3}$, Andino Maseleno ${ }^{4}$, Omar tanane ${ }^{5}$ \\ ${ }^{1,2}$ Department of Electrical Engineering and Informatics, Universitas Gadjah Mada, Yogyakarta, Indonesia \\ ${ }^{3}$ Information Systems, University of Management and Technology, Pakistan. \\ ${ }^{4}$ Institute of Informatics and Computing Energy, Universiti Tenaga Nasional, Malaysia. \\ ${ }^{5}$ Faculty of Sciences Ben M'sik, University Hassan II of Casablanca, Casablanca, Morocco \\ megantoro.prisma@gmail.com¹, danarauliahusnan@gmail.com², usman.sattar@umt.edu.pk ${ }^{3}$, \\ andimaseleno@gmail.com ${ }^{4}$, omar.tanane@univh2c.ma ${ }^{5}$
}

\begin{abstract}
Research on the design of fuel measuring device for vendors using Arduino Mega 2560 microcontroller and positive displacement flow meter sensor was conducted to design and create a prototype of a fuel measuring device for retail traders and find error values on the device. The research began with searching for reference books, making hardware and programming, and testing the device. The components used were an Arduino Mega 2560, a positive displacement flow meter sensor, a keypad, a solenoid valve, and a 4x20 LCD. The test was carried out by comparing the results of the measuring cup to the number displayed on the $L C D$, followed by reproducibility. Data collection was carried out every $500 \mathrm{ml}, 1000 \mathrm{ml}, 1500 \mathrm{ml}$, and $2000 \mathrm{ml}$. The results of the research showed that the error value was $2.24 \%$ with a comparison of $1.91 \%$. Several factors affecting the highness of error value were a human factor, sensor and device factor, as well as the comparison device being used. Referring to the error value that was smaller than $5 \%$, this device was worthy of mass production.
\end{abstract}

\section{Keywords-flow meter, calibrator, Arduino}

\section{INTRODUCTION}

Based on Law Number 2, the year 1981 concerning Legal Metrology, it is stated that to protect the public interest, there needs a guarantee in the measurement accuracy and order and legal certainty in the use of measurement units, standards, measurement methods, measuring instruments, weighing, and equipment. It is explained in the act that every item packaged, the actual weight content must be in accordance with the contents listed or printed on the label or package to provide protection to consumers and producers by giving a guarantee for the accuracy of measurement of units of Size, Scales and Equipment. The problem relating to retail fuel sales is the compatibility between the quantities contained in the container and the quantities that should be. Fuel vendors need a tool or device that can help them measure the quantity of fuel discharged effectively and accurately.

Several researchers have researched water flow measurements such as Saffari and Mirzakuchaki, who studied innovative smart packages for liquid flow meters [1]. Gosavi, Gawde, and Gosavi investigated an intelligent water flow monitoring and forecasting system [2]. The other researchers Rodgers et al. studied a $16-\mu \mathrm{A}$ interface circuit for capacitive flow sensors [3], while Comes et al. examined the ultrasonic flow estimator [4]. Jiang developed an intelligent flow totalizer based on an msp430 mixed single microcontroller [5], whereas Yang et al. designed and developed low power consumption ultrasonic open channel flow meters [6]. Akresh, Walker, and Reindl carried out flow measurement using the Kalman filter to smooth the frequency of vortex shedding [7], and Wang developed multi-path ultrasonic flow meters based on embedded systems [8]. Jiang et al. researched the MSP430 single chip low power smart gas turbine flow meter [9]. Shan conducted a micropower ultrasonic wave flowmeter study [10].

Some other research on flow sensors was conducted including the variance-based anti strong vibration interference method for vortex flow sensors by Chun-Li Shao, Ke-Jun $\mathrm{Xu}$, and Min Fang [11] and microcontrollerbased capacitance meters for two-phase flow sensors by Arunkumar, Venkatesan, and Kannan [12]. Research on controls and measurements was also carried out such as flow Wireless water flow monitoring based on Android smartphones by Jamaluddin et al. [13], a variable rate energy meter with automatic power flow control by Verma and Shandilya [14], and an intelligent flow meter in acoustic multivibrator by Sukhinets et al. [15]. The uncertainty of the measurement of closed-loop control systems for water flow rates was investigated by Prakosa, Putov, and Stotckaia [16], research on the water meter reading system based on LoRa communication was investigated by Li et al. [17], a study on a smart water meter was carried out by Sharath et al. [18]. Utomo et al. studied the process of making CLC (Cellular Lightweight Concrete) bricks using neural networks and microcontroller-based extreme learning methods and the visual studio [19]. Mohamed et al. improved the efficiency of smart water meters based on the selection of the mounting position and longer battery life [20].

Based on the previous research that has been carried out, the research carried out by the author aimed to design and develop a fuel flow measurement tool needed by retail fuel traders. The background problem inspired the author to design such a device. This device used an Arduino microcontroller board equipped with a flow sensor. It was 
limited to error values, uncertainties, and corrections from the devices.

\section{METHOD}

The method used in carrying out research was planning, conducting, checking, and evaluating. Underlining it, the research involved literature reviews, device and material preparation, design, hardware manufacture, programming, testing, and data analysis.

Figure 1 shows the tube used as a part of the device. It has the specifications of $12 \mathrm{~L}$ volume, $25 \mathrm{~cm}$ height, $25 \mathrm{~cm}$ diameter, and $1.1 \mathrm{~mm}$ thickness. The material is aluminum. A microcontroller is used for processing media performance, a solenoid valve for controlling the flow of fuel oil, and a flow sensor for detecting or measuring the flow of fuel oil.

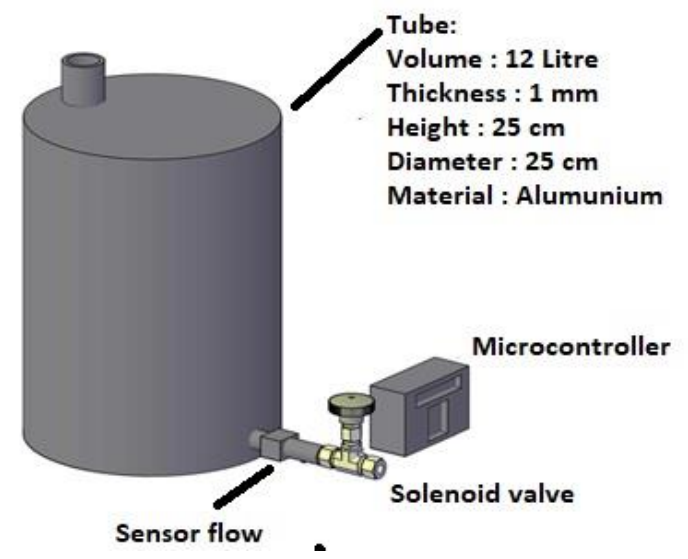

Fig. 1. Device design

\section{a. Hardware design}

Figure 2 illustrates the Arduino Mega [21] - [23] board connected to the Pins used. The pins are the LCD Pin, Keypad Pin, Relay Pin, and Sensor Flow Pin.

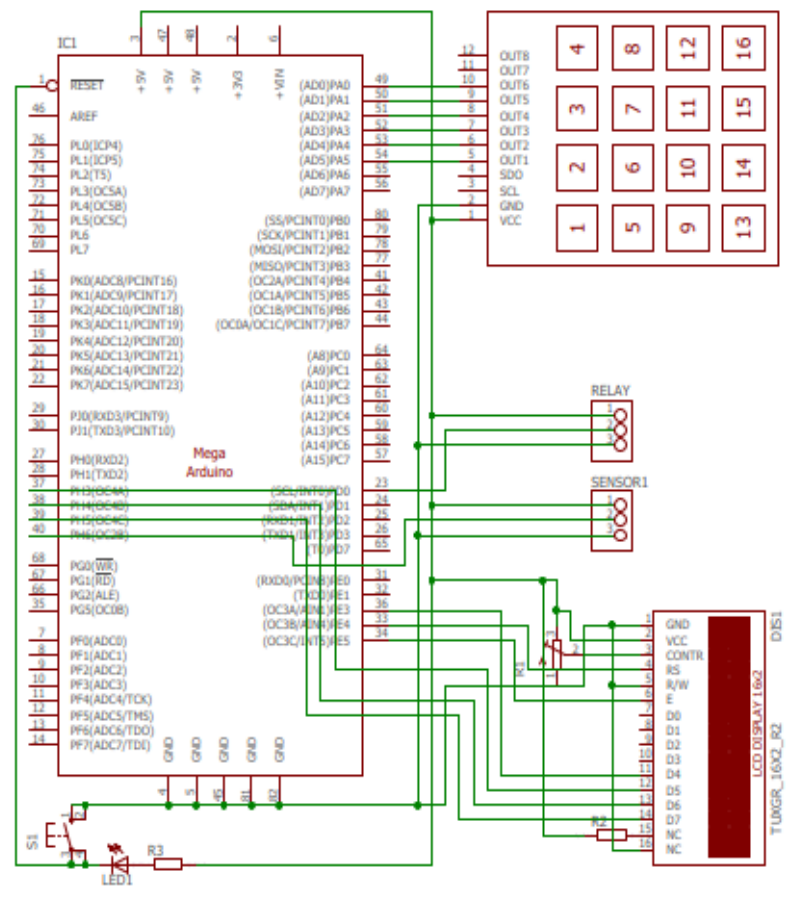

Fig. 2. Electrical device scheme
The microcontroller board used was Arduino Mega 256 type [24]-[28]. The programming of the device performance was made with Arduino IDE. As the input program, a 4x4 keypad was used to input the volume of fuel released by the device. The OF10ZAT type flow sensor was used to detect the fuel volume. The device used a solenoid valve as an actuator operated with a $12 \mathrm{~V}$ center. Opening and closing the actuator was managed by the processing carried out by the program. The measurement results were displayed on the 4x20 LCD screen [29] [30].

\section{b. Software design}

Software design on a system is very necessary for the system to run well. The software design on the proposed measuring instrument used Arduino/C language. For the programming on the keypad, the instructions are as follows:

- key A: Purchase by volume

- key B: Purchase by the amount of money

- key C: Purchase manually (Open Valve)

- key D: Purchase manually (Close Valve)

- key \#: Starts running Commands

- key *: Reset all commands

Figure 3 displays the instructions for the program. The first step is entering the input command. Then, the microcontroller controls the flow of the fluid by opening or closing the valve. After pressing the key \#, the program opens the valve, and the fluid starts to flow. When the valve opens, the flow sensor reads the fluid flows.

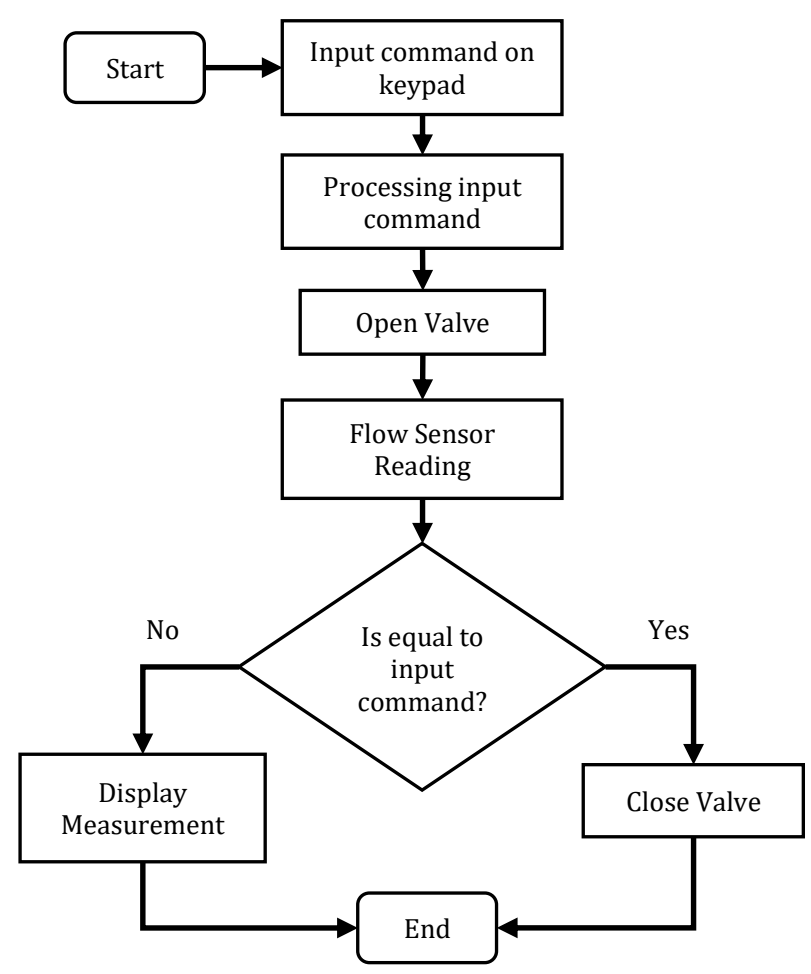

Fig. 3. System flow chart program

The data from flow sensor reading are processed by the microcontroller. If the valve still opens and the reading results 
are still following the input command, the program will display the discharge readings continuously on the LCD. Conversely, if the sensor readings are not under the input command, the program will assume that the valve opening is sufficient and close the valve.

\section{RESULT AND DISCUSSION}

The implementation of the research was carried out by a series of tests: hardware, software, and user interface tests as follows.

\section{a. Sensor test and characterization}

Figure 4 illustrates the sensor test and characterization were carried out to know whether the sensor can read the volume passing through the sensor and whether the Arduino Mega 2560 can read and process the data from the sensor. The following is the experiment of the sensor with Arduino Mega 2560. The test was carried out using Pertalite oil and reproducibility with two testers.

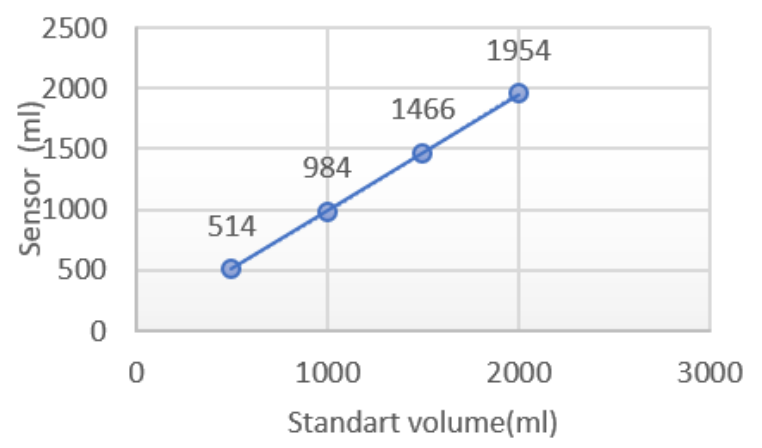

Fig. 4. Test on the reproducibility of the sensor

It can be concluded based on the graph in Figure 4 that the reading of the instrument toward the measuring cup has a rather large error value. At $500 \mathrm{ml}$, the reading is $514 \mathrm{ml}$ with the error value $+14 \mathrm{ml}$, at $1000 \mathrm{ml}$, the reading is $984 \mathrm{ml}$ with the error value $-16 \mathrm{ml}$, at $1500 \mathrm{ml}$, the reading is $1466 \mathrm{ml}$ with the error value $-34 \mathrm{ml}$, and at volume $2000 \mathrm{ml}$, the reading is $1954 \mathrm{ml}$ with the error value $-46 \mathrm{ml}$. The error value on the graph is increasing or directly proportional to the increase in volume.

The data presented in Table 1 show that each increase in the volume generates a greater percentage of an error value. In $1000 \mathrm{~mL}$ to $2000 \mathrm{~mL}$ volume, the percentage has increased by up to $0.70 \%$. However, in $500 \mathrm{~mL}$, the percentage is $2.80 \%$. The percentage is large because the reading is large too, but the error value is positive.

TABLE I. ERROR DATA TEST

\begin{tabular}{|c|c|}
\hline M1 & $\%$ \\
\hline 500 & 2.80 \\
\hline 1000 & 1.60 \\
\hline 1500 & 2.27 \\
\hline 2000 & 2.30 \\
\hline
\end{tabular}

The graph in Figure 5 illustrates that the greater the test volume, the greater the uncertainty value of the device. The uncertainty test was done by searching for the combined uncertainty. It was a test of all six uncertainty factors. It would be used to test the expanded uncertainty of the device as the final uncertainty values. The method of calculating the combined uncertainty was by considering all factors from the initial uncertainty square added to the uncertainty square.

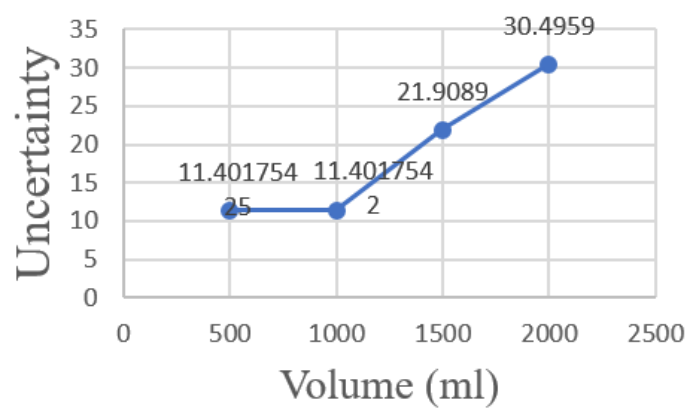

Fig. 5. Uncertainty comparison

Table 2 presents that the largest combined uncertainty value is the $2000 \mathrm{ml}$ volume test, and the smallest combined uncertainty is the $500 \mathrm{ml}$ and $1000 \mathrm{ml}$ volume tests. The last uncertainty test is expanded uncertainty. The combined uncertainty formula was used to find this uncertainty and then multiplied by the coverage factor obtained from finding the value of $\mathrm{V}$ reference.

TABLE II. COMBINED UNCERTAINTY

\begin{tabular}{|c|c|}
\hline Test $(\mathrm{ml})$ & Combined \\
\hline 500 & 5.107 \\
\hline 1000 & 5.107 \\
\hline 1500 & 9.802 \\
\hline 2000 & $1 ., 641$ \\
\hline
\end{tabular}

Table 3 presents that the biggest uncertainty is the $2000 \mathrm{ml}$ volume test, which is 27.287 , and the smallest uncertainty is the $500 \mathrm{ml}$ and $1000 \mathrm{ml}$ volume tests, which is 10.216 . The device has type B uncertainty. The next step was searching for Type B uncertainty. The type B uncertainty was obtained from the comparison of measured values to the specifications of the sensor. The value of the OF10ZAT model sensor specifications was $\pm 2 \%$, and the error reading was $1.917 \%$. These numbers were obtained from the average reading of test data. However, the percentage of each measurement shows error values that are very large than the average value of the data collection. Several things affected the accuracy of the device that was different from the specifications listed. The graph displayed the difference in readings made by examiner 1 and 2 is shown in Figure 6.

TABLE III. EXPANDED UNCERTAINTY

\begin{tabular}{|c|c|}
\hline Test $(\mathrm{ml})$ & Expansion \\
\hline 500 & 10.216 \\
\hline 1000 & 10.216 \\
\hline 1500 & 19.607 \\
\hline 2000 & 27.287 \\
\hline
\end{tabular}




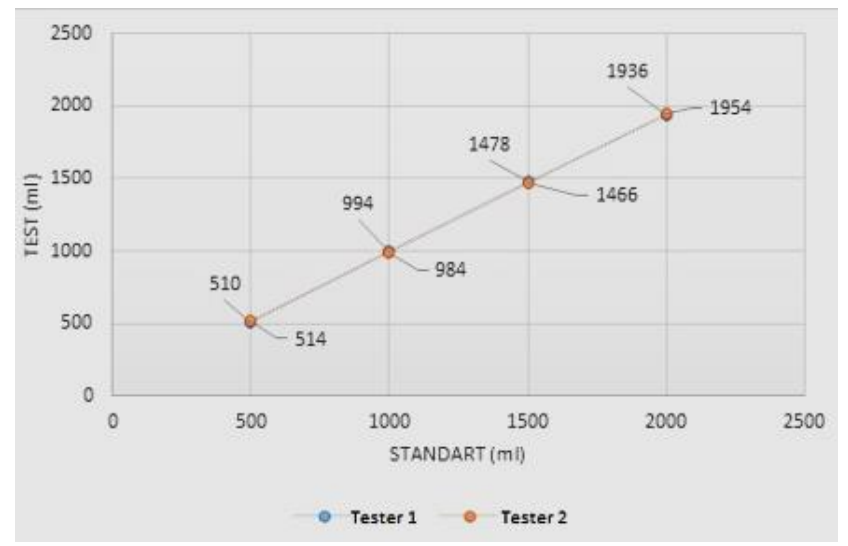

Fig. 6. Reading data from testers with the comparator

Figure 6 presents that the comparison of readings made by examiners 1 and 2 did not show much difference. The greatest difference between the readings was $21 \mathrm{ml}$. The data readings were influenced by the data retrieval was carried out using a measuring cup with a measuring range of $20 \mathrm{~mL}$. It greatly affected the results of the reading because the volume of fuel at the volume indicator was uncertain. The absence of a pump on the device affected the numbers of flowrate read by the sensor. There was no pressure that pushed oil down stably.

Figure 7 presents a user interface (UI) layout. The user interface on the device was a keypad to enter parameters or instructions. A $4 \times 20$ LCD was used to display command options and sensor readings.

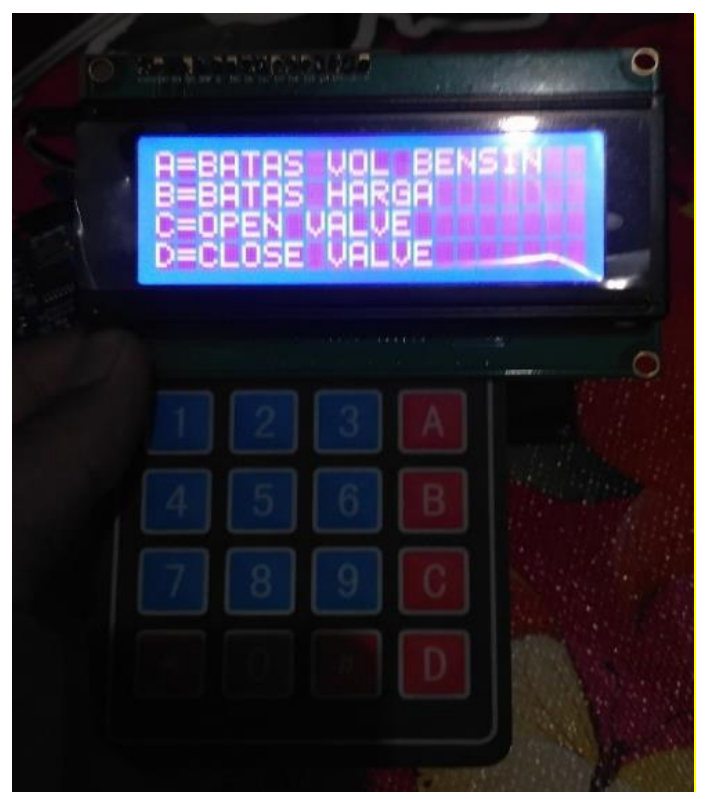

Fig. 7. UI layout

There are options A, B, C, and D on the keypad. The keypad A for purchases by volume, keypad B for purchases by the amount of money, and $\mathrm{C}$ and $\mathrm{D}$ for manual purchases. The LCD shows the amount of volume purchased, and the price to be paid.

\section{CONCLUSION}

The design of the volume measurement device for fuel vendors proposed in the research uses Arduino Mega 2560 type and positive displacement flow meter. The result shows that the device has good precision and accuracy. The test data show that the largest error value is -46 in $2000 \mathrm{ml}$ volume, while the comparative data shows that the largest error value is $-64 \mathrm{ml}$ in $2000 \mathrm{ml}$ value. The error value on the device is $2.24 \%$, in which the value is greater than the tolerance of uncertainty value determined at $0.5 \%$.

\section{REFERENCES}

[1] R. M. Saffari and S. Mirzakuchaki, "An innovative smart package for liquid flow meters," in 2017 Iranian Conference on Electrical Engineering (ICEE), 2017, no. 1CEE20 17, pp. 158-163.

G. Gosavi, G. Gawde, and G. Gosavi, "Smart water flow monitoring and forecasting system," in 2017 2nd IEEE International Conference on Recent Trends in Electronics, Information \& Communication Technology (RTEICT), 2017, vol. 2018-Janua, pp. 1218-1222.

[3] B. Rodgers, S. Goenawan, M. Yunus, Y. Kaneko, and J. Yoshiike, "A 16- $\mu \mathrm{A}$ interface circuit for a capacitive flow sensor," IEEE J. Solid-State Circuits, vol. 33, no. 12, pp. 2121-2133, 1998.

[4] M. Comes, P. Drumea, M. Blejan, I. Dutu, and A. Vasile, "Ultrasonic Flowmeter," in 2006 29th International Spring Seminar on Electronics Technology, 2006, pp. 386-389.

[5] Y. Jiang, "Intelligent Flow Totalizer Based on MSP430 Mixed Single Microcontroller," in 2007 IEEE Sensors Applications Symposium, 2007, no. February, pp. 1-6.

[6] S. Yang, G. Liang, W. Zhao, D. Xie, and Z. Huang, "Design of lowpower consumption ultrasonic open channel flow meter," in 2009 9th International Conference on Electronic Measurement \& Instruments, 2009, pp. 1-999-1-1002.

[7] M. Akresh, W. D. Walker, and L. Reindl, "Flow measurement using Kalman filter for smoothing vortex shedding frequency," in 2010 IEEE Instrumentation \& Measurement Technology Conference Proceedings, 2010, pp. 234-237.

[8] Y. Wang, "Development of multi-path ultrasonic flow meter based on embedded system," in IEEE ICCA 2010, 2010, pp. 689-692.

[9] Y. Jiang, Y. Yang, J. Xu, and Y. Liu, "Research of Low Power Intelligent Gas Turbine Flow Meter Based on MSP430 Single Chip," in 2010 WASE International Conference on Information Engineering, 2010, vol. 3, pp. 19-22.

[10] H. Shan, "Study of Micro Power Ultrasonic Wave Flow Meter," in 2013 Fourth International Conference on Digital Manufacturing \& Automation, 2013, pp. 1245-1248.

[11] Chun-Li Shao, Ke-Jun $\mathrm{Xu}$, and Min Fang, "Frequency-Variance Based Antistrong Vibration Interference Method for Vortex Flow Sensor,” IEEE Trans. Instrum. Meas., vol. 63, no. 6, pp. 1566-1582, Jun. 2014.

[12] S. Arunkumar, M. Venkatesan, and V. Kannan, "Microcontroller based Capacitance Meter for a Two Phase Flow Sensor," in Fifth International Conference on Advances in Recent Technologies in Communication and Computing (ARTCom 2013), 2013, vol. 2013, no. 645 CP, pp. $75-83$.

[13] A. Jamaluddin, D. Harjunowibowo, D. T. Rahardjo, E. Adhitama, and S. Hadi, "Wireless water flow monitoring based on Android smartphone," in 2016 2nd International Conference of Industrial, Mechanical, Electrical, and Chemical Engineering (ICIMECE), 2016, pp. 243-247.

[14] S. K. Verma and A. Shandilya, "Variable tariff energy meter with automatic power flow control," in 2017 International Conference on Energy, Communication, Data Analytics and Soft Computing (ICECDS), 2017, no. 2, pp. 58-61.

[15] Z. A. Sukhinets, A. I. Gulin, O. I. Bureneva, N. N. Prokopenko, and O. O. Valiamova, "Intelligent Flow Meter on Acoustic Multivibrator," in 2019 IEEE East-West Design \& Test Symposium (EWDTS), 2019, pp. 1-5. 
[16] J. A. Prakosa, A. V. Putov, and A. D. Stotckaia, "Measurement Uncertainty of Closed Loop Control System for Water Flow Rate," in 2019 XXII International Conference on Soft Computing and Measurements (SCM)), 2019, pp. 60-63.

[17] Y. Li, X. Yan, L. Zeng, and H. Wu, "Research on water meter reading system based on LoRa communication," in 2017 IEEE International Conference on Smart Grid and Smart Cities (ICSGSC), 2017, pp. 248-251.

[18] V. C. Sharath, S. Suhas, B. N. S. Jain, S. B. V. Kumar, and C. P. Kumar, "Smart aqua meter," in 2014 International Conference on Advances in Electronics Computers and Communications, 2014, pp. $1-5$.

[19] D. P. Utomo et al., "CLC (Cellular Lightweight Concrete) brick making process using neural network and extreme learning method based on microcontroller and Visual Studio.Net," in 2017 International Symposium on Electronics and Smart Devices (ISESD), 2017, vol. 2018-Janua, no. 1, pp. 79-84.

[20] K. A. Mohamed, M. G. Munier, P. P. William, S. A. Nagar, and A. M. A. Ibrahim, "Enhanced Smart Water Meter Efficiency Based on Mounting Position Selection and Extended Battery Life Time," in 2018 International Conference on Computer, Control, Electrical, and Electronics Engineering (ICCCEEE), 2018, pp. 1-6.

[21] S. Z. B. Zaharudin, M. Kazemi, and M. B. Malarvili, "Designing a respiratory $\mathrm{CO}<\mathrm{inf}>2</ \mathrm{inf}>$ measurement device for home monitoring of asthma severity," in 2014 IEEE Conference on Biomedical Engineering and Sciences (IECBES), 2014, no. December, pp. 230-234.

[22] M. R. Islam, Y. I. Asif, J. Rahman, S. Das Shuvo, A. Imran, and N. Jahan Prithee, "A Prominent Smart Gas Meter," in 2018 2nd International Conference on Electronics, Materials Engineering \& Nano-Technology (IEMENTech), 2018, pp. 1-7.

[23] G. Aurilio, D. Gallo, C. Landi, M. Luiso, V. Cigolotti, and G. Graditi, "Low cost combined voltage and current transducer for Smart Meters," in 2014 IEEE International Instrumentation and
Measurement Technology Conference (I2MTC) Proceedings, 2014, pp. 1459-1464.

[24] Mohd Adli Ikram Shahrulakram and J. Johari, "Water storage monitoring system with $\mathrm{pH}$ sensor for pharmaceutical plants," in 2016 6th International Conference on System Engineering and Technology (ICSET), 2016, pp. 46-52.

[25] B. Sithole, S. Rimer, K. Ouahada, C. Mikeka, and J. Pinifolo, "Smart water leakage detection and metering device," in 2016 IST-Africa Week Conference, 2016, pp. 1-9.

[26] M. R. Usikalu, B. M. Allen, W. A. Ayara, and I. O. Babarimisa, "Design of Autocrash Emergency Locator," in 2018 IEEE Conference on Technologies for Sustainability (SusTech), 2018, pp. $1-4$.

[27] M. S. Verdadero, R. B. Salon, and J. C. Dela Cruz, "INTELLIGENT GLOVE (iGLOVE) for Traffic Enforcers," in 2018 IEEE 10th International Conference on Humanoid, Nanotechnology, Information Technology,Communication and Control, Environment and Management (HNICEM), 2018, pp. 1-5.

[28] Izhar, W. Xu, X. Wang, R. Wang, and Y.-K. Lee, "Low-Cost Micro Predictive Mean Vote (PMV) Sensor and its Application for Smart Personal Ventilation Systems," in 2019 IEEE 32nd International Conference on Micro Electro Mechanical Systems (MEMS), 2019, vol. 2019-Janua, no. January, pp. 841-844.

[29] Y. S. Yang and H. C. Kim, "Development of a miniaturized IV drip rate meter using optical sensors and fuzzy rule based detection algorithm," in Proceedings of the 20th Annual International Conference of the IEEE Engineering in Medicine and Biology Society. Vol.20 Biomedical Engineering Towards the Year 2000 and Beyond (Cat. No.98CH36286), 1998, vol. 4, no. 4, pp. 17951798.

[30] K. Mahmud, M. S. Alam, and A. Jobayer, "Design and performance evaluation of PIC16F77A microcontroller based fluid velocity meter," in 2013 IEEE Global High Tech Congress on Electronics, 2013, pp. 21-24. 